\title{
THE PREVALENCE OF PATOSPERMIA IN MEN AFTER HERNIA REPAIR
}

Article history:

Submitted 18 March 2019

Accepted 5 May 2019

\section{Andrey Protasov, Nina Kulchenko*, Igor Vinogradov, Mariya Navid}

\author{
Peoples' Friendship University of Russia (RUDN University), \\ Moscow, Russia
}

*Corresponding Author:kle_kni@mail.ru
Only a few articles indicate a change in reproductive function after inguinal hernia repair [7]. Animal studies have shown that non-tension inguinal hernia repair results in obstruction of vas deferens and impaired spermatogenesis in the testicle [3]. Currently, in Russia there are no reliable statistical indicators of the prevalence of male infertility in patients undergoing hernia repair in the groin region.

to evaluate the prevalence of patospermia in men after inguinal hernia repair.

\section{METHODS}

The study was retrospective. We've analyzed the medical documents of 472 men who went to the andrologist with complaints about the absence of pregnancy of the wife during the 2017. Inclusion criteria: changes in the spermogram, age 18-50 years, agreement with the processing of personal data. Exclusion criteria: varicocele, hydrocele, testicular tumor, changes in karyotype.

We evaluated the presence/absence of inguinal hernia repair in history, the duration of the postoperative period, the duration and nature of infertility, the main parameters of the spermogram (according to who criteria, 2010): the volume of ejaculate, the concentration of germ cells, the percentage of total mobile (category $\mathrm{a}+\mathrm{b}$ ), active mobile (category a) and normal morphological forms of sperm in all patients.

The statistical analysis was performed using spreadsheets "EXCEL" and "STATISTICA 6.0". The significance of differences between quantitative indicators was assessed using the Mann-Whitney test. Differences were considered significant at $\mathrm{p}<0.05$.

\section{RESULTS}

The age of all men was $32.4+8.5$ years. According to medical records, 67(14.1\%) men had a history of inguinal hernia repair. The duration of infertility in these patients was $3.6+1.2$ years. Right-sided inguinal hernia was diagnosed in $35(52,2 \%)$ patients, left-sided - in 26(38,8\%); double-sided in 6(8,9\%). In men who had previously had inguinal hernia repair, obstructive form of infertility was revealed more often - 38(56.7\%). Sperm counts are presented in Table 1.

The dependence of sperm parameters on the side of surgery is shown on the Fig. 1. After herniation on 
Table 1. Indicators of ejaculate in men with inguinal hernia repair in history

\begin{tabular}{l|l|l|l}
\hline Indicators of ejaculate & Patients after inguinal hernia repair $(\mathrm{n}=67)$ & WH0, 2010 & P value \\
\hline Semen volume (ml) & $2,1+0,8$ & $>1,5$ & $\mathrm{p}>0,05$ \\
\hline Sperm concentration (million/ml) & $9,3+2,7$ & $>15$ & $\mathrm{p}<0,05$ \\
\hline Progressive motility (a) \% & $19+8,5$ & $>32 \%$ & $\mathrm{p}<0,05$ \\
\hline Total motility (a+b) \% & $23,6+6,2$ & $>40 \%$ & $\mathrm{p}>0,05$ \\
\hline Morphology (normal form \%) & $1,4+0,8$ & $>4 \%$ & $\mathrm{p}<0,05$ \\
\hline Leukocytes (million/ml) & $0,5+0,3$ & $<1$ & $\mathrm{p}>0,05$ \\
\hline MAR-test (\%) & $12+6$ & $<50$ & $\mathrm{p}>0,05$ \\
\hline
\end{tabular}

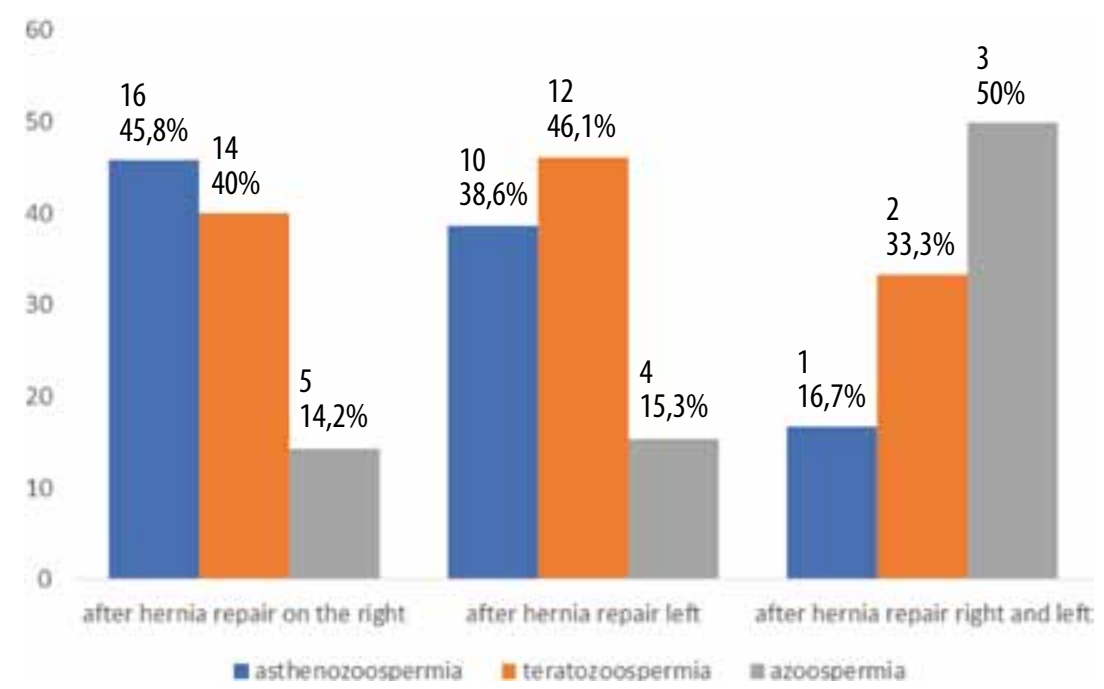

Figure 1. The dependence of sperm parameters on the side of hernia repair is performed $\left({ }^{*} p<0.05\right.$ azoospermia frequency in bilateral hernia repair compared with unilateral).

both sides, the parameters of the ejaculate were significantly worse in patients, in comparison with the performed hernia repair on the right or left sides $(p<0.05)$. There was no significant difference in the criterion of mobility and the number of normal morphological forms of sperm between patients with inguinal hernia repair on the right and left sides $(\mathrm{p}>0.05)$.

\section{DISCUSSION}

The modern methods of surgical treatment of hernias, including inguinal hernias, involves the operation using a synthetic implant (allogernioplasty), for prosthetics of functionally incompetent anatomical structures of the posterior wall of the inguinal canal [5, 8]. The question of the effect of inguinal hernia repair on spermatogenesis is still under discussion among specialists. The results of a large epidemiological study $(n=34267)$ for ten years in Sweden show that male infertility develops only in $0.7 \%$ of men after unilateral inguinal hernia repair [2]. However, the authors recognize that patients with bilateral hernia have an increased risk of infertility almost 5 times [2]. At the same time, the results of another randomized study showed that men after non-tension hernia repair had a tendency to reduce the concentration of sperm $(\mathrm{p}<0.05)$ [9]. Study by Khodari M. et al. herniation in the inguinal region is shown to cause obstructive azoospermia in $7.8 \%$ of cases [4]. According to Maciel L. C. et al. inguinal hernia repair is an operation that presents a potential risk of iatrogenic lesions of the vas deferens, especially in recurrent hernias.

Our study showed that after surgical treatment of inguinal hernia male infertility develops in every $7 \mathrm{men}$. We believe that the cause of pathospermia in men after inguinal non-tension hernia repair is edema of the spermatic cord, orchitis, inflammation of local tissues, which leads in most cases to obstruction of the vas deferens. Violation of spermatogenesis in men is global in Russia and around the world. Therefore, men of reproductive age after surgery in the groin need dynamic control of the spermogram and the supervision of not only the surgeon but also the andrologist.

\section{ONCLUSIONS}

Inguinal non-tension hernia repair is a risk factor for male infertility in $14.1 \%$ of men of reproductive age. After inguinal hernia repair the pathospermia in patients persists for more than 3 years (which means that not only in the early but also in the late postoperative periods). After inguinal hernia repair the obstructive form of male infertility prevails. The most severe abnormalities in the semen analysis develops after bilateral hernia repair. 


\section{REFERENCES}

1. Charalambous M.P., Charalambous C.P. Incidence of chronic groin pain following open mesh inguinal hernia repair, and effect of elective division of the ilioinguinal nerve: meta-analysis of randomized controlled trials. Hernia. 2018; 22:401-409. doi: $10.1007 /$ s10029-018-1753-9

2. Hallen M., Westerdahl J., Nordin P., GunNARSSON U., SANDblom G. Mesh hernia repair and male infertility: a retrospective register study. Surgery. 2012; 151:94-98. doi: 10.1016/j.surg.2011.06.028.

3. Junge K., Binnebösel M., Rosch R., OtTinger A., STUmpf M., MüHLEnbruch G. Influence of mesh materials on the integrity of the vas deferens following Lichtenstein hernioplasty: an experimental model. Hernia. 2008; 12:621-626. doi: 10.1007/ s10029-008-0400-2

4. Khodari M., Ouzzane A., Marcelli F., Yakoubia R., Mitchell V., Zerbib P. Azoospermia and a history of inguinal hernia repair in adult. Prog Urol. 2015; 25(12): 692-697. doi: 10.1016/j. purol.2015.06.008

5. Klimov A.E., Popov V.S., Barchudarov A.A., YURIY A.V. Choice of Mesh Implants for Lichten- stein Plastic of Male in Reproductive Age. RUDN Journal of Medicine. 2018; 22 (3): 249-257. DOI: 10.22363/2313-0245-2018-22-3-249-257.

6. Maciel L.C., Glina S., Palma P.C. Histopathological alterations of the vas deferens in rats exposed to polypropylene mesh. BJU Int. 2007; 100:187-190.

7. Protasov A.V., Kalyakanova I.O., Kaitova Z.S. The Choice of Implant for Hernioplasty of Postoperative Ventral Hernias. RUDN Journal of Medicine. 2018; 22 (3): 258-264. DOI: 10.22363/2313-02452018-22-3-249-257.

8. Simons M.P., Smietanski M., Bonjer H., Bittner R., Miserez M., Aufenacker T., Fitzgibbons R., Chowbey P., Tran H., Sani R. International guidelines for groin hernia management. Hernia. 2018; 22(1): 1-165. doi: 10.1007/s10029-017$1668-\mathrm{x}$

9. Sucullu I., Filiz A.I., Sen B., Ozdemir Y., YuCEL E., SinAN H. The effects of inguinal hernia repair on testicular function in young adults: a prospective randomized study. Hernia. 2010; 14(2): 165-169. doi: $10.1007 /$ s10029-009-0589-8 